Portland State University

PDXScholar

Business Faculty Publications and

Presentations

The School of Business

$11-2004$

\title{
An Environmentally Enlightened Accounting
}

Jesse Dillard

Portland State University, jdillard@pdx.edu

Darrell Brown

Portland State University, darrellb@pdx.edu

Scott Marshall

Portland State University

Follow this and additional works at: https://pdxscholar.library.pdx.edu/busadmin_fac

Part of the Accounting Commons

Let us know how access to this document benefits you.

\section{Citation Details}

Published as: Jesse Dillard, Darrell Brown \& R. Scott Marshall (2005) An environmentally enlightened accounting, Accounting Forum, 29:1, 77-101, DOI: 10.1016/j.accfor.2004.12.001

This Post-Print is brought to you for free and open access. It has been accepted for inclusion in Business Faculty Publications and Presentations by an authorized administrator of PDXScholar. Please contact us if we can make this document more accessible: pdxscholar@pdx.edu. 


\title{
AN ENVIRONMENTALLY ENLIGHTENED ACCOUNTING
}

\author{
Jesse Dillard \\ School of Business \\ Portland State University \\ Portland, OR \\ jdillard@pdx.edu \\ Darrell Brown \\ School of Business \\ Portland State University \\ Portland, OR
R. Scott Marshall
School of Business
Portland State University
Portland, OR

Draft - Please do not quote without authors’ permission.

26 November 2004

We have benefited from the comments received from participants at the Accounting Research Workshop at Washington State University, three anonymous reviewers, and the editors of this special issue.

Published in: Accounting Forum; March 2009, Vol. 29 Issue 1, p. 77-101 


\begin{abstract}
Environmental stewardship must become a primary concern if management is to adequately fulfill its societal responsibilities. Management and accounting information systems must aggressively respond to these emerging requirements in order to support adequately the associated information needs as well as to design organizational systems that motivate and facilitate desired behavior. Our purpose here is to consider a framework useful for developing environmentally enlightening management and accounting information systems that take into account alternative environmental perspectives. The framework can be used to develop prototypes representing different levels of environmental enlightenment and, as such, can provide general guidance for moving collectives and organizations toward a more environmentally responsible posture. The framework is illustrated using an example from the salmon farming industry provided in Georgakopoulos and Thomson (2004).
\end{abstract}

(keywords: enabling accounting, environmental responsibility, environmental strategy, sustainability) 


\section{AN ENVIRONMENTALLY ENLIGHTENED ACCOUNTING}

\section{INTRODUCTION}

Because of the devastating effect of unbridled industrial growth and development throughout the world, environmental issues are becoming significant societal risk factors. In the wake of countless disasters and the progressive degradation of the earth's ecosystems, society is beginning to demand a modicum of environmentally responsible behavior on the part of business management. Traditionally, the primary source for motivating environmentally responsible behavior has been through regulation based on government mandate. Recently, there at least appears to be a growing willingness of some, albeit small, groups of consumers to demand that companies refrain from egregious and wantonly irresponsible and exploitative behavior. As a result, the environmentally related issues with which a work organization is held accountable has expanded beyond those associated with the failure to comply with regulation to include missed market opportunities from not accurately anticipating consumer demand, failure to live up to societal expectations with respect to environmental stewardship, and, in some cases, the destruction of sustaining resources.

While all members of society have a moral responsibility to act in the public interest, organizational management is specifically granted fiduciary responsibility over society’s economic resources, which consist of natural resources, financial assets, human assets, and technology. The accounting profession facilitates and monitors organizational management's fiduciary responsibility and in this role is concerned with the integrity, responsibility, and accountability of the related financial and administrative systems and those who design, 
implement, and utilize them. The academic accounting community has a responsibility to facilitate, and actively engage in, a dialogue among all affected stakeholders regarding how accounting (the profession, the professionals, the systems) and organizational management can fulfill their responsibilities. In the following discussion, we address specifically management's, and therefore accounting's, responsibility with respect to environmental resources. Our long term goal is to initiate inclusive and enlightened dialogue directed toward articulating and communicating what constitutes reasonable and responsible environmental stewardship as a basis for bringing about change. Here, we outline and apply a framework useful for articulating action space parameters that frame management decisions and, therefore, for developing environmentally enlightened management and accounting information systems.

We situate this project as part of the enabling accounting project (Broadbent, et al., 1997), ${ }^{1}$ which is concerned with how accounting can be mobilized to advance the wellbeing of the earth and those critters that inhabit it. We wish to operationalize accounting as a force for social change through its potential for making actions and outcomes visible and comprehensible. As such, accounting can help stimulate dialogue and action directed toward change (Gallhofer and Haslam, 1997) as well as provide the mechanisms that engender responsibility and accountability. We envision accounting as having the potential as a positive force facilitating the development of viable and emancipatory ways for bringing about democratic social progress. Specifically, following a somewhat pragmatic, yet critical path (Bebbington, 1997), here we are about (re)making accounting information systems environmentally enabling by rendering visible and understandable the context of organizational decisions and implications of these resulting

\footnotetext{
${ }^{1}$ Also see the special edition of Accounting, Auditing and Accountability Journal, 1997 devoted to enabling accounting.
} 
actions on natural systems. This discussion fits within a genre of work that is beginning to critically address environmental accounting. ${ }^{2}$

As environmental awareness grew in the 1960s and 1970s, legislative initiatives began to gesture toward supplementing market solutions to ecological degradation. As a result, pollution emissions exceeding the regulatory limits represented the primary environmental considerations for business organizations. The regulatory reporting requirements associated with monitoring production processes specified information requirements. Selecting pollution control devices represented management's primary environmental concern. As best, accounting's function was generally associated with developing acquisition costs comparisons and projecting the effects on operating costs.

As the environmental implications of industrialization became more apparent, the scope and possibilities of environmentally related decisions expanded, as did the associated information requirements. As external stakeholders became more enlightened and involved, decision makers faced formidable environmental issues beyond those typically related to operations. For example, even though production processes were within the allowable regulatory limits, certain products and/or processes offended the sensibilities of environmental activists and their sponsors. As a result, companies were forced to consider these factors. An illustrative example occurred in the tuna industry in the late 1980s. While harvesting tuna using nets lethal to ensnared dolphins was not illegal, the impact of activists and consumers motivated three major name brand US tuna canning companies to switch to “dolphin-safe” harvesting methods even though this change increased the company's operating costs. In other words, management has been forced to consider issues and constituencies outside the traditional value chain, and as a

\footnotetext{
${ }^{2}$ See Gray (2002) for a review.
} 
consequence the associated accounting information systems must capture and report an expanded information set in order to motivate and enable responsible action.

Management’s environmental strategy must be made visible and comprehensible, and the implications of management's decisions must be specified. Further, formal corporate information systems must incorporate environmentally relevant information forcing management to consider the environmental impact of their operations and actions inclusive of, but also moving beyond, the economic implications. Such an environmentally enlightened perspective (Orr, 1994, Shuman, 2000) incorporates issues beyond, and sometimes in opposition with, maximizing shareholder value. Organizational management must recognize its societal responsibility as the operators of the primary natural resource transforming vehicle within the current social order and, as such, fulfill its stewardship responsibility with respect to natural systems. As such, management must formulate and implement environmentally impregnated strategies and information systems that enable and sustain such strategies. The following discussion represents an initial phase of an ongoing, iterative process specifying the strategic processes and fully articulating the information needs. Specifically, we consider three general levels of environmental sensitivity ${ }^{3}$ and discuss the information requirements along an environmental activity space ranging from a narrow focus on operations to an inclusive focus encompassing all relevant stakeholders.

There has been a limited, but expanding, concern with environmental reporting in the accounting literature. The more traditional work has focused primarily on the efficacy of socially responsible investing with environmental considerations only one of many factors (Gray, 2002). Stone (2001) has constructed a taxonomy of corporate social performance concepts useful in situating the various components and cites the work of Kinder, et al. (1993), Hamilton,

\footnotetext{
${ }^{3}$ We do not present these as inclusive, only as representative.
} 
et al. (1993), Diltz (1995), Guerard (1997), Belkaoui (1976), Abbot and Monsen (1979), Anderson and Frankie (1980), Ingram and Frazier (1983), Cowen, et al. (1987), Coffey and Fryxell (1991), Griffin and Mahon (1997) as relevant to the development of social and environmental accounting. ${ }^{4}$ Gray and Bebbington (2001) lay out in detail the issues relating to environmental accounting. As noted above, we take a somewhat pragmatic, critical path in an attempt to ultimately influence the revision, or reformulation, of management and accounting information systems in order to make the environmental implications of corporate actions transparent and comprehensible. The current discussion follows from, and is informed by, the alternative/critical accounting literature (see Gray, 2002 for a review) that includes Bebbington (1997), Bebbington, et al. (1999), Gray (1992), Gray, et al. (1994), Gray and Milne (2004), Everett (2004), Everett and Neu (2000), Lehman (1995, 1996, 1999, 2001, 2003), Power (1991, 1994), and Tinker, et al. (1991).

The ultimate objective of our research program is to develop an enabling accounting that representationally connects the organizations and the decision makers therein in a systematic way with the natural systems upon which they depend and upon which they act and as such to render the environmental implications visible and comprehensible. ${ }^{5}$ Here, we consider the composition of the environmental action space, which is presumed to be the intersection of the environmental activity space and what we refer to as the organization's logic of representation. The logic of representation refers to the organization's strategic orientation with respect to natural systems. We consider possible symbolic relationships associated with enlightened environmental management and the associated information requirements.

\footnotetext{
${ }^{4}$ Accounting studies addressing social performance measures and reporting standards include Rockness and Williams (1988), Davenport (2000), Clarkson (1995), Epstein, et al. (1976), Linitch, et al. (1989), Gamble, et al. (1995). Descriptive studies include Mathews (1993), Burke (1980), Ingram (1978), Tennyson, et al. (1990), Pava and Krausz (1995), Ingram and Frazier (1980); Wiseman (1982), Rockness and Williams (1988). The following studies consider the extent of environmental disclosure (Linitch et al., 1998; Li et al., 1997).

${ }^{5}$ See Brown, et al. (2004a), Marshall, et al. (2004), Brown, et al. (2004b).
} 
First, we consider the theoretical connection between natural systems and social systems, indicating how social systems have come to dominate and exploit the natural systems. This discussion provides a general theoretical base for framing the interface with, and the interactions between, natural systems, socially constructed abstractions, and organizational action. The principle differences between social systems and natural systems ultimately arise from the human being's facility for purposeful action facilitated by the capacity for symbolic representation and manipulation. These symbolic representations can be objectified and concretized as technology, expertise, and hierarchical control (Bauman, 1987, Adams and Balfour, 1998) in the process of transforming natural resources into useful goods and services. Management and accounting information systems are a particular kind of symbolic representation embodying expertise, facilitating hierarchical controls, and manifested as administrative technology that informs the purposeful action of organizations in the transformation process. These systems can foster sustaining processes, exploitative process, or some combination of both.

We briefly outline and then apply an environmental information matrix developed by Brown, et al., (2004a) in discussing the implications for developing enlightened management and accounting information systems. In describing the framework, we discuss alternative strategic perspectives as they relate to the time-space expansions of the various decision horizons. The resulting circumscriptions are useful in developing prototypes that represent different levels of environmental enlightenment, and as such, can provide general guidance for moving organizations toward a more enlightened posture. Here we focus primarily on the action space associated with an environmentally enlightened management perspective. Applying the framework assists in specifying the environmental action space employed by the Scottish salmon 
farmers in deciding whether to switch from traditional to organic farming methods. Final remarks bring the discussion to a close.

\section{LOGIC OF ENVIRONMENTAL REPRESENTATION}

We need some general conceptualization of the relationship between social systems and the natural system as a basis for enhancing the visibility and comprehensibility of organizational actions with respect to their environmental implications. Here, we consider the theoretical relationship between natural systems and social systems as articulated in the recent ecology literature (Hollings and Gunderson, 2002). According to this perspective, social systems (i.e., humans and their intentionality) have come to dominate and exploit natural systems. However, we propose that capabilities facilitating the current exploitive attitude can be refocused and employed to sustain and restore the natural system. Environmentally enlightened accounting and reporting plays a central role in this refocusing and redeployment as it frames and reframes organizational action space.

Comparing the natural system with social systems, Westley et al. (2002) note that social scientists and ecologists tend to have different orientations toward natural systems as they relate to social systems. The ecologists see systems of human beings and nature as ecosystems (i.e., people + nature $=$ ecosystems) while the social scientists conceive of systems of human beings and nature as social systems (i.e., people + nature $=$ social systems). The ecologists argue that both culture and nature fall on an inclusive continuum of natural processes. The social scientists conceive of nature as a component in the political discourse of human processes and as such it warrants no special consideration. In fact, to be recognized within the social system, the factor must be changed to a form compatible with the language of the social system. Only as the natural system components are commodified can they be incorporated into the neoclassical 
economic calculus. We hold that while the natural system and social systems are separate they are inextricably interrelated and that the symbiotic relationships between the elements of these two self organizing systems must be acknowledged and represented in the information systems of business organizations to facilitate responsible decision making on the part of organizational management. We refer to these systemic relationships as ecosystems in an attempt to motivate thinking beyond the current, homocentric perspective.

The question arises as to the dimensions of organization and behavior along which the representations should be constructed. For ecosystems, temporal and spatial dimensions represent the fundamental constructs that have been used by ecologists to explain the self organizing dynamics of ecosystems (Levin, 1992). Holling and Gunderson (2002) argue that when studied over time and space, the reproductive/adaptive cycle of ecosystems can be represented through the dynamic interaction of the potential (stored up energy) contained in the system, the degree to which the elements in the system are connected, and the system's resilience to change. ${ }^{6}$ The capability for acting purposefully is dependent upon the ability to accommodate higher levels of system complexity. Higher levels of systems complexity requires higher levels of abstract representation, which in turn enhances the social system’s flexibility. Natural systems do not possess the capability of symbolic representation and, therefore, of abstraction, reflexivity, projection, or technology. As a result, these systems cannot act knowledgeably and with intentionality.

While the reproduction of social systems includes similar parameters, the distinguishing feature between the two systems is human beings’ facility for symbolic

\footnotetext{
${ }^{6}$ Holling and Gunderson (2002) propose a three dimensional model of the adaptive cycle of ecosystems within which they argue social systems can be incorporated. A full discussion of this model is tangential to this discussion. The interested reader is referred to Gunderson and Holling (2002) for a complete discussion of this model and examples of its applicability to various ecosystems.
} 
representation and manipulation. Social systems are the product of symbolic representation and manipulation in time and space. Language represents the prototypical example of this symbolic capacity and how rules, relationships, values, and resources can be directed across time and space. Following from this capacity, the result of the actions and interactions of the participating agents construct complex social systems (e.g., Searle, 1995). These social systems constitute, and are constituted by, the ability to: communicate, in the broadest sense; administer rewards and sanctions based on the shared norms and values; and accomplish goals through control over both physical and human resources. Further, unlike natural systems, social systems must be produced and reproduced through the purposeful, reflexive actions of the populating agents. ${ }^{7}$ As such, purposeful actions of the agents constitute and can change social systems.

Westley, et al. (2002) discuss four characteristics or capabilities that follow from human being’s symbolic facility: abstraction, reflexivity, projectional models, and technological manifestations. Symbolic representation allows humans to attribute meaning and assign value to activities and anticipated activities and to abstractly represent social and physical worlds. That is, these systems and their components can be represented in a simplified, symbolic way that allows for the "experiences" to be removed from the "site," reflected upon, manipulated, and saved. This provides for the construction of hierarchies of abstraction and, therefore, learning and extrapolation. Abstraction allows the agent to give meaning to, to re-construct, the local context. Thus, the action space within which the agent operates is constructed through the application of the particularly configured symbolic hierarchies. Unless these abstractions can be connected to, and/or grounded in, the natural systems along relevant dimensions, the controlling representations may take a dangerously narrow or distorted view of the implications. For example, economic systems are a construct of social systems. If economic abstractions dominate

\footnotetext{
${ }^{7}$ See Giddens (1984).
} 
and are not connected to natural systems, the decision making criteria do not reflect the potential ecosystem implications. If organizational representations are framed only by the symbolic hierarchies of the economic system, then the actions taken based thereon will not consider their implications for the natural system.

Reflexivity refers to the agent's ability to monitor with purposeful intent action over time and space. Symbolic representation permits the manipulation of symbols (meaning) such that outcomes are evaluated relative to values, goals, and norms that may be contained within, and represented by, the symbolic hierarchies. Future actions are preceded by, and predicated on, ongoing evaluation and as such evaluations and actions influence the reproduction of the social systems within which the flow of actions take place over time and space.

Representation and monitoring over time (learning) result in a clustering of symbols coalescing into classifications (knowledge structures) such that these representations can be employed in anticipating future actions and their implications (the action space). It is as though the values of the "variables” within a representational cluster can be changed in responding to a series of "what if" questions that project the effects of anticipated future actions as well as provide criteria for reflexively analyzing and evaluating the subsequent outcomes. Forward projections coupled with the reflexive monitoring of actions using the representational clusters allows for the development of a logic of representation for both the social and natural worlds and their interrelationships. This logic (symbolic representations and the rules for their manipulation) provides the space for action. These are the organizing principles for social integration and therefore action. ${ }^{8}$ For example, the formal and informal environmental strategies

\footnotetext{
${ }^{8}$ Logic of representation is analogous to the application of schema, frames, or metaphor (Schank and Ableson, 1977; Lakoff and Johnson, 1998) in that it provides, at least partially, a generally-specified and "standardized" context for confronting a certain class of problems or circumstances. This logic is enabling in that it provides general characteristics and structure and constraining in that it restricts the representational alternatives.
} 
that comprise the space within which managers consider, and act on, environmental issues constitute the logic of representation for addressing environmental issues within a particular organization at a particular time. This logic is both constraining and enabling, inclusive and exclusive.

Westley, et al. (2002) argue that one material consequence of human beings' symbolic capabilities is the ability to externalize this culminating logic or perceived understanding by embodying the logic in technology. The result is a material objectification of the abstract representation. ${ }^{9}$ Problems arise as the technology becomes objectified without proper reflexive self-regulation capabilities. More specifically, the logic of representation does not recognize or meaningfully connect to the natural system. Thus, the technological applications are "single variable interventions” (117), do not contain mechanisms for systematic self-monitoring and regulation, and do not balance competing objectives. As a result, the technological application becomes unidirectional and exploitative of the natural system. Depending upon the nature of the system and the duration and severity of the exploitation, the applications of the technology can result in the ultimate collapse of the natural system and, thus, the entire ecosystem.

We see the consequences of single variable interventions in such examples as holes in the ozone layer, global warming, and the use of DDT as a pesticide. The representations of the social system, by focusing on the objects of the technology (refrigerant capabilities of CFCs, consumable energy from fossil fuels, and greater monoculture crop yields, respectively) failed to consider the impacts on the related natural system. By relying strictly on the limited representations of the homocentric social systems, information concerning the impacts on the natural systems is omitted, leading to potential ecological catastrophes that have, and will, impact the related social systems.

\footnotetext{
${ }^{9}$ This material representation may be subjective objectification such as financial derivatives (see Macintosh, et al. 2000).
} 
What this says is social systems, as a result of their inhabitants' agency, have the ability to impose their will on the natural system ${ }^{10}$ because of the potential for purposeful action. The abstract representations of purposeful intentions can be reified and mobilized in the form of technology, either scientific or administrative. Technology translates into power to transform and control, enhance and destroy. The logic of representation enacted by organizational actors determines how power is allocated and implemented. If the purposeful intent of the social system is exploitative, oriented toward growth and wealth accumulation, and dominated by economic logic, then the technologies will be alien and exploitative with respect to natural systems and social systems components.

So, what are the implications here? We believe that the same symbolic capabilities that can close off and exploit to the point of destroying natural systems (and ultimately social systems as well) can also be employed in understanding and sustaining those systems. In order to do so, the actors must recognize the possibility and the need for change and understand the means for undertaking it. For the desired change to take place, there must be a revision of the norms and values held by the actors such that the economic criteria are supplemented, sustained, or replaced, by more inclusive and enlightened criteria that directly connect to sustaining dimensions of natural systems. Further, change requires that resources be redirected by the new norms and values and the related richer representation structures. In other words, the logic of representation must be modified to reflect an enlightened appreciation of the natural systems and the processes necessary to sustain and enrich these systems. Articulated within the vernacular of the prevailing social system, the logics of representation must incorporate a recognition of what have been euphemistically termed externalities. In the next section, we add specificity to these

\footnotetext{
${ }^{10}$ More precisely, social systems have the ability to alter the natural systems in ways that can reduce or eliminate the viability of the social system. Humans have not yet developed the capability to destroy (or save) the earth; we have only developed the capability to destroy our ability to survive on the earth.
} 
rather abstract ideas by discussing the alternative representational logics, identifying the information needs associated with these alternative approaches to environmental stewardship, and providing evaluation criteria.

\section{THE ENVIRONMENT ACTION SPACE}

In this section, the environmental action space is articulated by employing components of an environmental information matrix developed in Brown, et al. (2004a). The previous work focuses on management information system requirements needed in supporting various environmentally related decisions. Here, we are concerned with circumscribing the environmental action space associated with alternative management representational logics. The purpose of specifying the action space is both prescriptive and diagnostic: prescriptive in that it provides a guide for expanding environmental responsibility and diagnostic in that the framework can be used to gauge the level of environmental responsibility accepted by an organization. To reiterate, mapping the action space is an initial step in conceptualizing the linkages between organizational actions and their implications for the natural system and vice versa. First, we describe three alternative environmental logics of representation (how) followed by a discussion of the scope of decision inclusivity (who) associated with the environmental activity space. Next, we consider the composition of an environmentally enlightened action space (what) and associated information components. Figure 1 provides a general representation of the environmental action space.

$$
* * * * * \text { Enter Figure } 1 \text { here } * * *
$$

\section{Logic of Representation}

The corporate social responsibility literature classifies organizational environmental strategy along a continuum ranging from no consideration for environmental issues to 
recognizing environmental issues to be of central importance (Bansal and Roth, 2000; Hart, 1995; Hunt and Auster, 1990; Roome, 1992; Hernriques and Sadorsky, 1999). In the following discussion, we consider three strategic specifications: legitimacy, competitive advantage, and enlightened management. While we discuss these alternatives as separate characterizations, we recognize that they lie along a continuum upon which specific demarcation points cannot be clearly delineated.

\section{Legitimacy}

Legitimacy reflects a minimalist environmental strategy. ${ }^{11}$ If the organization adopts a legitimacy strategy, the objective is to maintain its position in the industry and the referent community, situating it such that environmental related actions will not negatively effect the firm's operations. The primary focus is preserving its legal and social license to practice by meeting regulatory requirements and providing no compelling environmentally related reasons to deny the firm operating rights (Bansal and Roth, 2000; Hernriques and Sadorsky, 1999). The organization seeks parity and social license through its environmental practices, not advantage and preference. The ultimate decision criteria is to enhance the input-output ratio by balancing the organizational costs and benefits of externalizing transformational costs.

\section{Competitive Advantage}

Implementing a competitive advantage environmental strategy attempts to improve its market and economic position (Bansal and Roth, 2000; Hart, 1995) as a result of environmentally related actions. Environmentally desirable behavior represents a tool for improving profitability. For example, the firm may achieve higher efficiencies or higher quality as a result of environmentally related actions by improving its processes (Klassen and Whybark,

\footnotetext{
${ }^{11}$ Given that within today's political and regulative climate organizational management cannot ignore environmental issues, we presume this strategy to represent the minimum feasible strategic position.
} 
1999; Lovins, Lovins, and Hawkens, 1999; Porter and van der Linde, 1995b). Also, the firm may establish new markets, gain additional market share, and/or increase market size through environmentally related product development, product improvements, and increased customer loyalty (Hart and Milstein, 2000; Porter and van der Linde, 1995a). The primary focus is enhanced economic results. Environmental resources are seen as inputs to a transformation process that is to be carried out in the most economically efficient manner. Maximization of owner/shareholder wealth represents the ultimate decision criteria. Enacting environmental policies and actions are viewed as a means to an economic end.

\section{Enlightened Management}

Environmentally enlightened management conceives of the organization as primarily an ecologically sustainable, and sustaining, entity as opposed to solely an economic one. Environmental considerations, instead of being opposed to maximizing economic value, constitute the primary long term decision parameters. Strategic objectives are predicated on long term sustainability objectives rather than profitability goals. Management believes that the firm must act in environmentally responsible ways to insure its long term preservation (Starik and Rands, 1995, Gladwin, et al., 1995). Enlightened management contemplates alternative courses of action in light of whether by carrying out the anticipated actions the organization can achieve environmental sustainability by creating and producing products and services that are consistent with the long term regenerative capacities of renewable resources and absorptive capabilities of the ecosystem (Gladwin, 1993; McDonough \& Braungart, 2002; Kiuchi \& Shireman, 2002).

\section{The Environmental Activity Space}

The environmental activity space relates to the scope of the decision processes and encompasses the time, space, and inclusivity parameters associated with organizational actions. 
Here, we are concerned with the environmental implications of organizational actions; therefore, we have specified this dimension slightly differently than in Brown, et al. (2004a). There our perspective was that of the manager and what information was needed to facilitate decision making. As such, we defined this dimension as an expanding decision horizon. Here, we are concerned with the environmental scope of management decisions so we specify this dimension as relating to the range of ecological impact considered within the resulting action space. These parameters circumscribe the social and environmental ${ }^{12}$ implications considered by decision makers in contemplating action from a given strategic perspective. Again for illustrative purposes, we choose three prototypical designations for environmental activity space: operational, customers/markets, and stakeholders/society.

\section{Operations}

The environmental scope of the operations activity space focuses primarily on relationships and processes within the boundaries of the firm. The activities tend to be directly related to, or the result of, operations. Discharging greenhouse gases into the atmosphere is a direct result of operations and can also result in reduced production or product costs. In most cases, these decisions require initiation and implementation only within the organization, and the motivations for these actions are inwardly focused and based primarily on a relatively immediate financial impact. Generally, the decision horizon for the operations related decisions have a relatively short time horizon, and the operating impact begins to dissipate quickly after discontinuing the activities. ${ }^{13}$ Those directly involved are either members of the organization or those who are in direct contact with it, geographically and/or interactively.

\footnotetext{
${ }^{12}$ We are primarily considering the environmental outcomes here but also wish to recognize their interrelatedness and interdependence with the social systems.

${ }^{13}$ This does not limit the implications to the short term but suggests that some tangible change becomes evident relatively quickly. An example of this would be the dumping of toxic waste into a waterway. Though the total impact may be realized over a long period of time, there is an immediate interface with, or imposition on, the natural systems as a result of the actions.
} 


\section{Customers/Markets}

The scope of the customers/markets activity space includes activities that fall within the context of the firm's markets and delineates the considered environmental implications to those relating to the firm's markets. Consideration moves beyond the organization itself and reaches the organization's customers, suppliers, regulators, and competitors, all of whom may be affected by the changing market conditions. The activities involve processes both internal and external to the firm. As a result, the implementation time would be generally longer because controlling and coordinating the activities of external constituencies becomes more problematic and the residual effect on cost and benefits will more likely be longer than those associated with operational activities. Although there may be immediate environmental implications, market activity space activities generally implicate more sustained relationships and thus a broader impact than those associated with operations.

\section{Stakeholders/society}

The environmental scope of the stakeholders/society activity space extends the boundaries to include societal implications and considers the firm's actions with respect to a wide range of traditional and nontraditional stakeholders. This activity space recognizes the implications of actions on both natural and social systems, both currently and in the future. The time dimension is long term, and the space dimension is inclusive. Activities within this activity space include internal and external processes, which may involve relationships across organizational and institutional boundaries. The activities are evaluated with respect to their anticipated long term impact and affect on long term relationships and are associated with long term commitments and investments of social and economic resources. 


\section{Environmental Action Space as Nexus}

The environmental action space is comprised of the intersection of the logic of representation and the environmental activity sphere. A complete representational response would include the three logics of representation categories and the three activity space categories that can be represented as a three by three matrix as shown in Figure 2. Since our purpose is to begin to articulate a framework for developing an environmentally enlightened accounting, we will develop the action space represented by the nexus of the enlightened management.

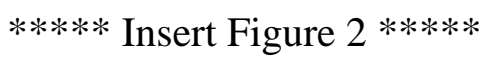

\section{A Framework for an Environmentally Enlightened Accounting}

The purpose of developing environmentally enlightened accounting systems is to render these systems as a positive force in the pursuit of progress toward environmentally responsible action. Within such a system, environmental factors are primary and determining in that the environmental implications are viewed as an end, and not a means or an impediment, to economic ends. Enlightened management views the objective of the entity or enterprise as environmentally sustainable and sustaining. This perspective is directly and actively concerned with the relationship between natural systems and social systems, of which the economic system is a subset. We propose this as the only viable, long term strategic perspective and that by such a perspective requires, and is enabled and sustained by compatible systems. Below, we discuss information indicators associated with such an enlightened perspective, which provide an indication of what the associated information system needs.

The enlightened perspective requires a fundamental shift relative to the other two strategic perspectives. For the legitimacy and competitive advantage logic of representation, market related economic factors are the primary considerations and dominate the action space. For the enlightened management perspective, the economic is subordinated to the needs of both 
the natural and social systems. This so called paradigm shift requires much more inclusivity, moving beyond an individualist, utilitarianism focus toward a more holistic, communal perspective. As the philosophical shift takes place, the environmental action space shifts and expands. The decision considerations migrate away from operational and economic indicators toward indicators signifying the impact of the organizational acts on natural systems.

Information systems are redesigned and expanded to support needs, reflecting the organization's impact on, and implications for, natural systems. Next, we discuss the information dimensions associated with an enlightened management perspective. An environmentally enlightened accounting would be expected to incorporate these components. The framework for an environmentally enlightened accounting is broad in scope encompassing all three activity specifications. Each is considered from a perspective that privileges the environmental over the economic. As such, traditional accounting measures must be extended or directly supplemented. Specific examples of items that might be included are presented in Figure 3.

\section{***** Enter Figure 3 here $* * * * *$}

\section{Operations}

The operations related issues are probably the most obvious and include such things as measures of various characteristics of toxic waste such as amount, concentrations, types, and alternative production processes. Energy consumption represents another central environmental consideration associated with operations and requires indicators concerned with the total amount of energy consumed, the availability of energy from renewable resources, and how much of the total energy use is, or could be, from these sources. Other considerations include energy usage, and possible savings associated with such activities as employee commuting and business travel. The incremental costs of improving facilities and buildings' energy efficiency ratings as well as 
design and construction using alternative energy sources and recycled, or recyclable, materials illustrated over the relevant environmental information.

An environmentally enlightened system might also include the design cost and administration of environmental management systems (EMS). These systems specifically represent the impact of organizational actions on the natural system and include information concerning volume of emissions and effluent outputs by unit of production, by source and in aggregate, as well as the toxicity rating of effluents and emissions. These are directly related to the production process and are designed to provide information well beyond the minimum regulatory requirements required by extant regulatory regimes. As a result, the cost incurred would probably be greater than that required for only monitoring regulatory minimum.

\section{Customer/Market}

Within the customer/market activity space, the focus shifts from internal, operational concerns to more externally oriented product related concerns. ${ }^{14}$ The organization considers ways in which to design, distribute, and sell its products and services in an environmentally responsible manner. For example, an environmentally enabling accounting information system considers the availability and cost of renewable energy for product in-use, as well as the energy consumption over the product life cycle. Another important issue deals with the availability of renewable and/or recyclable materials and product components. The percentage of products that are recyclable and/or reusable as well as the cost of related take-back systems are also relevant.

\section{Stakeholder/society}

The scope of the activity space broadens beyond those groups directly related to the firm and the immediate natural environment to include a larger set of stakeholder groups and long-

\footnotetext{
${ }^{14}$ This is not to imply that these decisions do not influence production and operational decisions, only that at this level, these effects are more a response to customer/market prescriptions.
} 
range environmental implications. Environmental impact constitutes the primary decision criteria. The time, space, and social dimensions expand and the project perspective may take on the characters of a long range project, not unlike traditional capital budgeting projects and/or long range planning exercises. An accounting information system that supports environmentally enlightened management focuses on the long term relationships between the organization, the natural environment, and the broader community and recognizes that these relationships are predicated on mutual cooperation, not self interested competition. Processes must be developed that facilitate effective schemes for identifying and involving stakeholders in organizational decisions such as facility location and processes, product, and infrastructure design.

Any decision with long-term implications requires projections of the future environmental impacts. The long term projections involve recognizing, measuring, and monitoring local, regional, and global environmental conditions and determining the potential impact of alternative courses of action. Associated issues include cost of monitoring and measuring the status of environmental conditions, transboundary and bioaccumulative impacts, carbon offsets, and life cycle analyses. Management must be sensitized to, and supported in, such decisions, and there must be information systems in place to facilitate and support these decisions. For example, cogeneration and co-location represent an environmentally enlightened project that requires an expanded decision making perspective in that potential partners must be identified with respect to location and waste output compatibility, alternative production models developed, and the environmental implications specified.

Next, we apply the environmental action space framework to an environmentally sensitive case situation involving the salmon farming industry in Scotland. We use the framework to structure the representation so as to better understand the environmentally related 
issues and the associated motivations for actions taken. We also tentatively gesture toward possible improvements in the information systems based on the framework's prescriptions.

\section{ORGANIC SALMON FARMING}

Georgakopoulos and Thomson (2004) report the results of a series of interviews with Scottish salmon farmers and other participants in the Scottish farming industry concerning the context, processes, perceived risk, and information relevant to the farmers shifting from traditional farming processes to organic production methods. ${ }^{15}$ Their initial purpose of the work was to study the environmental accounting techniques and practices used by the salmon farmers in making the decision to change from traditional to organic salmon farming. However, the results indicate the farmers employed no such practices or techniques. The authors' found that the decision to switch to organic production methods was: driven by intuitively derived price expectations and the possibility for long term sales contracts for the end product; perceived to be relatively easy, inexpensive and nonproblematic; not a reaction to criticisms of damaging the environment; and not influenced by accounting costs, techniques, or evaluations (Georgakopoulos and Thomson, 2004, 6).

Three salient themes emerged from the on site interviews: risk construction; how the perceived risks affected the decision to change; and the patterns of communication between the industry and various stakeholders (Georgakopoulos and Thomson, 2004, 7). The interviews also indicated that regulatory compliance was equated to good environmental performance, thus the participants felt that no additional consideration of environmental factors is necessary. Further, the participants perceived that there were heavy sanctions imposed for noncompliance. Any

\footnotetext{
${ }^{15}$ We presume that organic salmon farming is more ecologically responsible and sustaining than traditional farming techniques and is therefore preferable from an environmental standpoint. This is not to say that the current organic farming practices cannot be further developed, or replaced, to better facilitate long term sustainability. As reported by Georgakopoulos and Thompson (2004), see Highlands \& Islands Enterprise \& the Scottish Office (1998), Hities, et al. (2004), Larid andNeedham (1988), Mills (1989), ORGSAL (2000) and Sutherland (2000), also www.soilassociation.org.uk.
} 
possible environmental damage was attributed to larger competitors and was associated with large scale production processes. (Georgakopoulos and Thomson, 2004, 16-17). “Going organic” depended upon opportunism, forecasted price premiums, and risk reduction.

Environmental criticisms had no direct influence on the decision nor was the change preceded by a change in farmers' values with respect to ecological concerns (Georgakopoulos and Thomson, 2004, 15).

It appears that the migration toward organic farming can be characterized as small, flexible producers identifying and exploiting a niche market within the commercial salmon industry. The participants spoke of their inability to compete with the large firms in the traditional markets and the perceived enhanced profitability opportunities within the organic market sector. Further, the transition was relatively easy for some of the smaller producers. Concern was voiced by the industry association as to the long term viability of such a change. Georgakopoulos and Thomson (2004) indicate that the legitimating business rhetoric of the farmers was not accompanied by accounting data, formal evidence, or costs analyses (18) which apparently did not play a role in the decision.

Georgakopoulos and Thomson (2004) found little concern for the physical, social, or aesthetic values associated with organic aquaculture, and the end customer was not part of the decision process, only those parties with whom the farmers have direct market relationships. There was no acknowledgement that organic production might result in a better product or a reduction in the potential negative health implications. The decision appears to have been a straightforward agribusiness decision based strictly on rudimentary economic considerations (23). 
Georgakopoulos and Thomson's (2004) results indicate clearly that the farmers' decision to change from traditional salmon to organic production methods was not the result of enhanced awareness and concern over environmental issues. The farmers' initial considerations were with costs and standards of operations. As the market matured and expanded, market issues came to dominate. Environmental outcomes were not considered other than as required by regulatory and certification bodies. For the farmers, organic salmon farming represented a means to an economic end. Ironically, the regulatory and certification procedures appeared to provide a means whereby the producers felt justified in abdicating responsibility for the environmental impact of their actions asserting that by satisfying the requirements set forth by the regulatory agencies the farmers had satisfied any obligation they might have with respect to sustainable environmental practices. There was no indication that the farmers were approaching an enlightened management perspective even though their actions were consistent with minimal sustainability tenets. However, without a change at the motivational level, any environmentally sustaining change is assured only as long as it is aligned with the economic logic dominating the action space. Georgakopoulos and Thompson (2004) analysis indicates a need for an environmentally enlightened accounting, not an example of one. In order to facilitate permanent change, a shift in perspective must occur such that environmental initiatives take precedence over operational and economic initiatives. The result would be a (re)formation of the environmental action space.

Next, we consider how such a change might be contemplated. First, we discuss the case within the context of the environmental action space. Then we address possible attributes of an environmentally enlightened accounting. 


\section{An Application of an Enlightened Environmental Framework}

We consider how an environmentally enlightened action space might frame the decision by Scottish Salmon farmers to change from traditional salmon processing to organic salmon processing. An environmentally enlightened action space, and therefore an environmentally enlightened accounting, requires that both the economic and environmental implications of the salmon farming processes be captured and represented. We suggest that if such a framework and the accompanying information system were in place, the likelihood of more sustained environmentally responsible management would be increased.

Traditional salmon farming can be detrimental to the natural systems. ${ }^{16}$ Genetically modified fish are used posing risks to the health of natural stocks. The primary food source is low quality fishmeal fortified with chemical additives. Flesh coloring techniques are also used to enhance the appearance of the fish. High stocking densities result from the use of small cages, and the farmers use blanket chemical treatments for parasites and diseases. These practices are associated with nonsustainable aquaculture practices in the region and have resulted in damage to the marine environment as well as damage to wild salmon populations. Further, these practices appear to yield an increasingly contaminated product offered for human consumption.

Organic salmon farming processes mitigate some of the detrimental environmental effects of traditional salmon farming by: eliminating the use of genetically modified fish; substituting higher quality fish meal for the low quality, chemically enhanced products; alleviating the need for flesh coloring techniques; using larger cages lowering the stock density; and eschewing blanket chemical treatments.

As noted above, economic implications of salmon farming dominate the current environmental action space. The perceived benefits of organic salmon production include higher

\footnotetext{
${ }^{16}$ As reported in Georgakopoulos and Thompson (2004), also see Highlands \& Islands Enterprise \& Scottish office (1998).
} 
prices, higher margins, and higher profitability facilitated by an increased likelihood of the farmers negotiating guaranteed sales contracts and exclusive sales agreements with major purchasers such as grocery stores, lower competition and greater independence through a more clearly differentiated product, and a reduced chance of sales collapses due to publicity from future contaminated food scares or protests. Further, where economic factors dominate the action space, economic risks can motivate farmers to abandon the organic farming processes. The economics associated with organic salmon farming includes high production costs, the threat from foreign competition and weak markets for organically cultivated fish and smolt, limited growth within the organic markets, and difficulties in gaining financing because of these uncertainties associated with organic farming.

We propose that the implications of the farmers' actions predicted on economic factors be linked with their implications for the natural systems and that the link between the economic system and the natural system must take place within the social system. ${ }^{17}$ Here, human beings begin to reinterpret the effects of human actions on the natural systems, the incentives operating within the economic system, and the interrelationships between them. The extant regulatory and certification regimes reflect some minimum level of societal expectation with respect to management's responsibility for environmental stewardship and consequences for not meeting these responsibilities. However, current regulations may be inadequate lacking the flexibility necessary to respond as unexpected consequences arise that might render current practices unsustainable. Further, these regulatory regimes can act as impediments to progressive environmental practices, as in the case where the organic farmers point to their compliance with

\footnotetext{
${ }^{17}$ As noted earlier, we recognize that the economic system is a subset of the social system. However, we see the economic system as something that has been reified and separated from this grounding. As such, the economic system appears to operate independently and detrimentally relative to the social system and the natural systems, though in decidedly different ways.
} 
current regulations as evidence that they are fulfilling their environmental responsibilities and should not be further accountable.

As discussed earlier, we view the social system as the mechanism, both extant and potential, for facilitating system integration. By system integration, we mean the cooperative and complimentary actions among the economic, social, and natural systems. Given that only human beings have the capability for purposeful, intentioned action, as contrasted with the natural system’s exclusively reactive mode, social systems facilitate social integration through symbolic representation and manipulation (communication). Because of the homocentric inclinations of these processes, social systems have come to dominate the natural systems, potentially facilitating the collapse of the affected natural system. Further, certain representational logics are privileged over others. A given subsystem may be more amenable to a privileged representational logic, and as such, would tend to gain dominance. Within the prevailing social order, the economic system is an example of a dominant subsystem. Thus, social systems come to dominate natural systems, and economic systems come to dominate social systems. Georgakopoulos and Thomson’s (2004) depiction of the salmon farmers' decision to "go organic" bears out such a characterization. The salmon farmers formulate the people-nature equation of people plus nature as equating to economic factors. They seem to subsume the natural system into social systems and privilege the economic subsystem over the other social systems.

The conception and specification of the environmental action space resides within the social system and may be approximated by mapping the information structures contained therein. The temporal and spatial self organizing dynamics of the natural systems associated with salmon fishing do not appear to be explicitly considered by the salmon farmers. However, they are 
manifested in the issues previously discussed relative to the natural system impact. For example, high density farming methods have diminished the quality of farming sites damaging the ecosystems and weakening the native salmon population.

The salmon farmers’ representational logic provides insight into why they operate within such a narrow space. Within the dominant economic frame embraced, or imposed, by the salmon farmers, the temporal and spatial dimensions collapse into crude representations of profitability, representations provided by the traditional accounting system. There are two secondary representational collectives located in the social system: regulatory/certificate requirements and market forces. Both are the product of symbolic representation and manipulation over time and space. The former attempts to bridge economic and natural systems in order to protect and sustain both. The latter commodifies the natural system and treats it as a means to an economic end. The accounting system represents the natural system as a source of inputs and a repository for byproducts arising from the transformation process.

Both the regulatory regime and the market apparatus embody the constituting attributes associated with social systems: symbolic representations that create and communicate meaning and understanding; the ability to articulate shared norms and values and administer associated rewards and sanctions; and the facility for accomplishing goals through control over physical and human resources. The current regulatory/certification regime attempts to insure a sustainable aqua business environment by reducing the environmentally detrimental practices such as blanket chemical treatments for parasites and diseases, by monitoring stock density levels, and by prohibiting the use of genetically modified stock. Alternatively, the market mechanisms provide incentives based on representations of costs, profit margins, negotiated contract length, and price stability. While the implications for the natural system are significant, the only 
linkages with this system that enter this action space with respect to inputs are indirect and presumed to be impounded in the market price of the inputs. The only outputs recognized are the direct costs associated with the disposition of waste and byproducts. All other externalities are excluded.

Both regulatory and market representational regimes are predicated on, and provide the medium for, abstraction, allowing the actors to assign meaning and constitute local context. Obviously, the context constructed will be quite different. One at least attempts to reduce the impact on the natural system by articulating an action space linking action, implications, and motivations with the social system representations of their effect on the natural system. The other constructs an action space that privileges the economic linkages with associated market based outcomes, excluding any consideration for the sustainability of the natural system. This environmental action space circumscribes the reflexive scope of the actor. We argue that the restricted environmental action space associated with the market focus leads the salmon farmers to consider only the narrowly focused economic implications of their decisions. It is incidental to them that organic salmon farming might be instrumental in sustaining the natural system. Within this context, meeting certification requirements represent another set means for reaching an economic end.

Based on the information reported by Georgakopoulos and Thomson (2004), we classify the representational logic as most closely aligned with the environmental strategy of seeking competitive advantage with the environmental activity space being circumscribed by customers and markets. The market oriented perspective provides the criteria or space for action. It appears that this logic, at least from a natural system perspective, objectifies the economic representation and inhibits the reflexive capacity necessary to meaningfully connect actions with 
their natural system implications. We argue that the neoclassical economic "technology" provides no mechanism for environmental self monitoring and regulation and, therefore, cannot adequately consider, much less balance, sustainability objectives with economic ones. As a result, the considerations become unidirectional and exploitative. The salmon farmers exhibit this type of logic, and even though they have chosen to implement organic farming processes, it seems reasonable to presume, that if the market characteristics change such that organic farming becomes economically unattractive relative to traditional methods, the farmers would abandon the organic methods in favor of the traditional ones. Their current decision models/action space do not permit them to do otherwise. So, next we ask what would an enlightened management perspective and the associated accounting system look like within the organic salmon farming context.

\section{Toward an Environmentally Enlightened Accounting System}

As previously noted, we maintain that representational capacities of the social systems can be operationalized in making environmental implications visible and understandable and, therefore, in protecting natural systems. In order to realize this potential, the participants need to understand why change is desirable and the means by which it can be brought about. For the Scottish salmon farmers, their norms and values regarding the natural system would have to change. Economic decision criteria need to be integrated with, and subordinated to, environmentally sustainable ones.

Recognizing environmental implications as the primary and determining decision criteria must be viewed as the only viable long term perspective for the salmon farmers. Such an enlightened perspective requires a fundamental shift in the farmers' current environmental action

space. As illustrated above, the representational logic associated with the competitive advantage 
strategy dominates the decision criteria and thus the associated information cues used in decision making. The decision criteria must shift from price, profit margins, and market share to levels of toxic waste, natural resource depletion, and environmental sustainability. With respect to operations, salmon farmers need information systems that incorporate and monitor such dimensions as quality and environmental effects of fish meal and the chemical additives therein, the stock densities and the associated effluence implications, and the mortality rates from parasites and disease. Such measures provide environmental information beyond the minimum regulatory and certification requirements.

From a more proactive perspective, research and development efforts are directed toward identifying and developing more environmentally enhancing inputs and processes, resulting in aqua farming techniques that ultimately enhance the ecosystem, not just maintain it. Environmentally responsible market related decision criteria and information consider desirable product attributes (e.g., reduced mercury levels), energy efficient distribution channels, and organic product sales. Marketing programs focus on educating customers to the benefits of organically farmed salmon including the environmental impact. Reporting processes relate economic factors directly to environmental implications. Production processes and value chain analyses focus primarily on environmental sustainability as opposed to economic efficiency.

As a result, the decision horizon is broadened to include multiple stakeholder groups. Mechanisms are developed and put in place that facilitate input from, and meaningful interaction with, various constituency groups. For example, the salmon farmers would develop direct communication channels with the various environmental groups as well as members of the local and regional community. Input is solicited on a wide range of issues from operational decisions such as site location to long range ecological considerations such as the implications for wild 
salmon stock. Long range planning is driven primarily by the environmental implications of strategic initiatives and capital projects at local, regional, and global levels. An environmentally enlightened accounting and the accompanying information systems would be constituted of these relationships rendering the relationships more visible and comprehensible.

\section{FINAL COMMENTS}

In the preceding discussion, we illustrate how technology, in this case administrative systems and the associated information systems, might be framed such as to promote an enlightened, sustainable perspective of natural systems. We propose to ultimately link natural systems and economic systems through the representational lens of an environmentally enlightened enabling accounting information system. We discuss how through social abstractions and symbolic representations economic motivations can be associated with implications within natural systems. Specifically, we consider how management information systems (technology), as objective manifestations of subjective social system dynamics, have the potential to privilege economic considerations, natural considerations, or both. Establishing these linkages connotes a necessary condition for representing the effects of alternative environmental strategies on natural systems that will render these relationships more visible and understandable, ultimately leading to an increased level of accountability.

The steps implied for moving toward more enlightened environmental management are somewhat analogous to the evolution of environmental awareness and the perceived need for environmental stewardship by organizations and those who manage them. In the 1960's, leading organizations began to pay attention to environmental issues, basically due to the regulatory pressures. The organizational strategy generally adopted in response was a legitimating one focused on compliance and some minor avoidance behaviors, thereby ensuring that the firm 
could continue to operate. In the 1980's these organizations began to identify ways to improve their competitive advantage, both by reducing their overall costs through such actions as reducing inputs and by differentiating themselves from their competitors through adopting “green” initiatives motivated by a desire to improve their market position, the salmon farmers being a current example. Currently, some visionary organizations, though not the salmon farmers considered above, have adopted enlightened management behaviors following from the beliefs and desires of organizational management. These companies are usually private, with strong management control by a single individual or a small group of individuals. The management of such organizations often has an "epiphany” that results in significant changes in the operation of the organization. These organizations adopt a wide variety of environmental initiatives that may or may not be economically enhancing as measured by traditional financial indicators. In short, they have moved from organizations that "get by" to ones that "get rich" to ones that "get religion." If this is the case, we have much evangelizing to do if we are, literally, to save the world.

We have proposed a pragmatic approach to developing environmentally enabling accounting information systems. Articulating alternative environmental strategies and their anticipated outcomes represent incremental steps toward better conserving and sustaining ecosystems affected by the transformation processes of organizations. We do not propose this incremental approach as a solution to the fundamental problem of unbridled growth and accumulation, which will require radical political and social changes. However, we do feel that if taken seriously, further developed, and implemented, the proposed approach has the potential to retard the momentum of the currently irresponsible and exploitative trajectory. The proposed framework provides a general guide helpful in designing environmentally enabling management 
and accounting information systems that increase visibility and understanding and begin to raise awareness concerning the excesses currently being imposed upon the natural systems by the juggernaut of global capitalism. 


\section{REFERENCES}

Abbott, W., and R. Monsen. 1979. On the measurement of corporate social responsibility: Selfreported disclosures as a method of measuring corporate social involvement. Academy of Management Journal 22 (3): 501-515.

Adams, G. B. and D. L. Balfour. 1998. Unmasking Administrative Evil. Thousand Oaks, CA: SAGE Publications.

Anderson, J., and A. Frankle. 1980. Voluntary social reporting: An iso-beta portfolio analysis. The Accounting Review 55 (3): 467-479.

Bansal, P. \& K. Roth 2000. Why companies go green: A model of ecological responsiveness. Academy of Management Journal. 13(4): 717-736.

Bauman, Z. 1989. Modernity and the Holocaust. Ithaca, NY: Cornell University Press.

Bebbington, J. 1997. Engagement, Education and Sustainability: A Review Essay on

Environment Accounting. Accounting, Auditing and Accountability Journal. 10: 365-381.

Bebbington, K. J., Gray, R. H., \& Owen, D. L. 1999. Seeing the wood for the trees: taking the pulse of social and environmental accounting. Accounting, Auditing and Accountability Journal. 12(1): 47-51.

Beets, D., and C. Souther. 1999. Corporate environmental reports: The need for standards and an environmental assurance service. Accounting Horizons 13 (2): 129-145.

Belkaoui, A. 1976. The impact of the disclosure of the environmental effects of organizational behavior on the market. Financial Management 5 (4): 26-31.

Broadbent, J., Ciancanelli, P., Gallhofer, S. and J. Haslam. 1997. Enabling accounting: the way forward?” Accounting, Auditing, and Accountability Journal 265-275.

Brown, D., J. Dillard, and S. Marshall, 2004a. Strategically informed, environmentally conscious information requirements for accounting information systems. Proceedings $10^{\text {th }}$ AIS Research Symposium, Phoenix, AZ.

Brown, D., J. Dillard, and S. Marshall, 2004b. Triple bottom line: A business metaphor for a social construct. Working paper. School of Business Administration, Portland State University, Portland, OR.

Burke, R. 1980. The disclosure of social accounting information. Cost and Management (MayJune): 21-24. 
Clarkson, M. 1995. A stakeholder framework for analyzing and evaluating corporate social performance. Academy of Management Review 20 (1): 92-117.

Coffey, B., and G. Fryxell. 1991. Institutional ownership of stock and dimensions of corporate performance: An empirical examination. Journal of Business Ethics 10: 437-444.

Cowen, S., L. Ferreri, and L. Parker. 1987. The impact of corporate characteristics on social responsibility disclosure: A typology and frequency-based analysis. Accounting, Organizations and Society 12 (2): 111-122.

Davenport, K. 2000. Corporate citizenship: A stakeholder approach for defining corporate social performance and identifying measures for assessing it. Dissertation abstract. Business \& Society 39 (2): 210-219.

Diltz, J. 1995. Does social screening affect portfolio performance? Journal of Investing (Spring): 64-69.

Epstein, M., E. Flamholtz, and J. McDonough. 1976. Corporate social accounting in the United States of America: State of the art and future prospects. Accounting, Organizations and Society 1 (1): $23-42$.

Everett, J. 2004. Exploring (false) dualisms for environmental accounting praxis. Critical Perspectives on Accounting. 15:1061-1084

Everett, J. and Neu, D. 2000. Ecological modernization and the limits of environmental accounting. Accounting Forum. 24(1):5-30.

Gallhofer, S. and J. Haslam. 1997. Beyond accounting: The possibilities of accounting and 'critical' accounting research,” Critical Perspectives on Accounting. 71-95.

Gamble, G., K. Hsu, D. Kite, and R. Radtke. 1995. Environmental disclosures in annual reports and 10Ks: An examination. Accounting Horizons 9 (3): 34-55.

Geogakopoulous, G and I. Thomson. 2004. Organic salmon farming: Risk perceptions, decision heuristics and the absence of environmental accounting. Proceedings - Asia Pacific Interdisciplinary Research in Accounting. Singapore July 4-7.

Gladwin, T. N. 1993. The meaning of greening: A plea for organizational theory. In K. Fisher \& J. Schot (Eds.), Environmental strategies for industry: 37-61. Washington D.C.: Island Press.

Gladwin, T. N., Kennelly, J. J. and Krause, T. S. 1995. Shifting paradigms for sustainable development: Implications for management theory and research. Academy of Management Review, 20 (4): 874-907.

Giddens, A. 1984. The Constitution of Society. Berkeley: University of California Press. 
Gray, R.1992. Accounting and environmentalism: an exploration of the challenge of gently accounting for accountability, transparency, and sustainability. Accounting Organizations and Society, 17(5):399-425.

Gray, R. 2002. The social accounting project and Accounting, Organizations and Society: Privileging engagement, imaginings, new accountings and pragmatism over critique? Accounting, Organizations and Society 27: 687-709.

Gray, R. and J. Bebbington. 2001. Accounting for the Environment $2^{\text {nd }}$ Ed. London: Sage Publications.

Gray, R., Dey, C., Owen, D., Evans, R. and Zadek, S. 1997. Struggling with the praxis of social accounting: stakeholders, accountability, audits and procedures. Accounting, Auditing and Accountability Journal. 10(3): 325-64.

Gray, R. and Milne, M.J. 2004. Towards Reporting on The Triple Bottom Line: Mirages, Methods and Myths, In A Henriques and J. Richardson (eds.), The Triple Bottom Line: Does it All Add Up? London: Earthscan.

Griffin, J., and J. Mahon. 1997. The corporate social performance and corporate financial performance debate. Business and Society 36 (1): 5-31.

Guerard, J. 1997. Is there a cost to being socially responsible in investing: It costs nothing to be good? Journal of Investing 6 (2): 11-18.

Gunderson, L. and Holling, C. (eds.) 2002. Panarchy: Understanding Transformations in Systems of Humans and Nature., Island Press: Washington, D. C.

Hamilton, S., H. Jo, and M. Statman. 1993. Doing well while doing good? The investment performance of socially responsible mutual funds. Financial Analysts Journal (NovemberDecember): 62-66.

Hart, S. L. 1995. A natural-resource based view of the firm. Academy of Management Journal, 37: 986-1014.

Hart, S. L. \& M. B. Milstein. 2003 Creating sustainable value. Academy of Management Executive. 17(2) 56-69.

Henriques, I. \& Sadorsky, P. 1999. The relationships between environmental commitment and managerial perceptions of stakeholder importance. Academy of Management Journal, 42 (1): 8799.

Highlands \& Islands Enterprise and The Scottish Office. 1998. Final report: The economic impact of Scottish salmon farming. Public \& Corporate Economic Consultants (PACEC).

Hites, R., Foran, J., Carpenter, D., Hamilton, M., Knuth, B., and Schwager, S. (2004) Global assessment of organic contaminants in farmed salmon, Science, 303: 226 - 229. 
Holling, C. S. and Gunderson, L. H. 2002. Resilience and adaptive cycles, in Panarchy: Understanding Transformations in Systems of Humans and Nature. Gunderson, L. H. and Holling, C. S., eds., Island Press: Washington, D. C. (25-62).

Hunt, C. B. \& Auster, E. R. 1990. Proactive environmental management: Avoiding the toxic trap. Sloan Management Review, 31(2): 7-18.

Ingram, R. 1978. An investigation of the information content of (certain) social responsibility disclosures. Journal of Accounting Research 16 (2): 270-285.

Ingram, R. and K. Frazier. 1980. Environmental performance and corporate disclosure. Journal of Accounting Research 18 (2): 614-622.

Ingram, R. and K. Frazier. 1983. Narrative disclosures in annual reports. Journal of Business Research 11: 49-60.

Kinder, P., S. Lydenberg, and A. Domini. 1993. Investing for Good: Making Money While Being Socially Responsible. New York, NY: Harper Business.

Kiuchi, T. \& Shireman, B. 2002. What We Learned in the Rainforest: Business Lessons from Nature. San Francisco: Berrett-Koehler.

Klassen, R.D. \& Whybark, D.C. 1999. The impact of environmental technologies on manufacturing performance. Academy of Management Journal, 42(6): 599-615.

Laird L. and Needham T. 1988. Salmon and trout farming. Chichester: Ellis Horwood.

Lakoff, G. and M. Johnson. 1998. Philosophy in the Flesh. New York: Basic Books.

Lehman, G. 1995. A legitimate concern for environmental accounting. Critical Perspectives on Accounting. 6(6): 393-412.

Lehman, G. 1996. Environmental accounting: Pollution permits or selling the environment. Critical Perspectives on Accounting. 7:667-676.

Lehman, G. 1999. Disclosing new worlds: a role for social and environmental accounting and auditing. Accounting, Organizations and Society. 24(3): 217-242.

Lehman G. 2001. Reclaiming the public sphere: problems and prospects for corporate social and environmental accounting. Critical Perspectives on Accounting. 12:713-33.

Lehman, G. 2003. A critical perspective on the harmonisation of accounting in a globalising world. Critical Perspectives on Accounting

Levin, S. A. 1992. The problem of pattern and scale in ecology. Ecology 73(6): 1943-1967. 
Li, Y., G. Richardson, and D. Thornton. 1997. Corporate disclosure of environmental liability information: Theory and evidence. Contemporary Accounting Research 14 (3): 435-474.

Llinitch, A., N. Soderstrom, and T. Thomas. 1998. Measuring corporate environmental performance. Journal of Accounting and Public Policy 17 (4,5): 383-408.

Lovins, A. B., Lovins, L., \& Hawken, P. 1999. A road map for natural capitalism. Harvard Business Review, (May/June 1999): 145-158.

Macintosh, N., T. Shearer, D. Thornton, \& M. Welker. 2000. Accounting as simulacrum and hyperreality: Perspectives on income and capital. Accounting, Organizations, and Society. 25(1): 13-50.

Mathews, M. 1993. Socially Responsible Accounting. London, U.K.: Chapman \& Hall.

McDonough, W. \& Braungart, M. 2002. Cradle-to-Cradle: Remaking the Way We Make Things. New York: North Point Press.

Mills, D. 1989. Ecology and Management of Atlantic Salmon. New York: Chapman \& Hall Ltd.

ORGSAL. 2000. Organic Salmon production and consumption: ethics, consumer perceptions and regulation. University of Stirling.

Orr, D. 1994. Earth in Mind. Washington, D.C.: Island Press.

Pava, M., and J. Krausz. 1995. Corporate Responsibility and Financial Performance. Westport, CT: Quorum Books.

Porter, M. E. \& van der Linde, C. 1995a. Green and competitive. Harvard Business Review, (September-October): 120-134.

Porter, M. E. \& van der Linde, C. 1995b. Toward a new conception of the environmentcompetitiveness relationship. Journal of Economic Perspectives, 9 (4): 97-118.

Power, M. 1991. Auditing and environmental expertise: between protest and Professionalization. Accounting, Auditing \& Accountability Journal. 4(3):30-42.

Power, M. 1997. Expertise and the construction of relevance: accountants and the environmental audit. Accounting, Organizations and Society. 22(2): 123-146.

Rockness, J., and P. Williams. 1988. A descriptive study of social responsibility mutual funds. Accounting, Organizations and Society 13 (4): 397-411.

Schank, R \& R. Abelson. 1977. Scripts, Plan, Goals, and Understanding. Hillsdale, NJ: Erbaum. 
Searle, J. (1995). The Construction of Social Reality. New York: The Free Press.

Shuman, M. 2000. Going Local. New York: Rougledge.

Stone, B. A. 2001. A special-purpose taxonomy of corporate social performance concepts. Accounting in the Public Interest, 1(1): 42-72.

Sutherland R. 2000. Organic salmon: a preliminary analysis of the economic issues. SAC.

Tennyson, B., R. Ingram, and M. Dugan. 1990. Assessing the information content of narrative disclosures in explaining bankruptcy. Journal of Business Finance \& Accounting 17 (3): 391410.

Tinker T, Lehman C, Neimark M. (1991) Falling down the hole in the middle of the road: political quietism in corporate social accounting. Accounting, Auditing, and Accountability Journal. 4(2):28-54.

Westley, F., Carpenter, S. R., Brock, W. A., Holling, C. S. and Gunderson, L. H. 2002. in Panarchy: Understanding Transformations in Systems of Humans and Nature. Gunderson, L. H. and Holling, C. S., eds., Island Press: Washington, D. C. 103-119.

Wiseman, J. 1982. An evaluation of environmental disclosures made in corporate annual reports. Accounting, Organizations and Society 7 (1): 53-63. 
Figure 1. Environmental Action Space

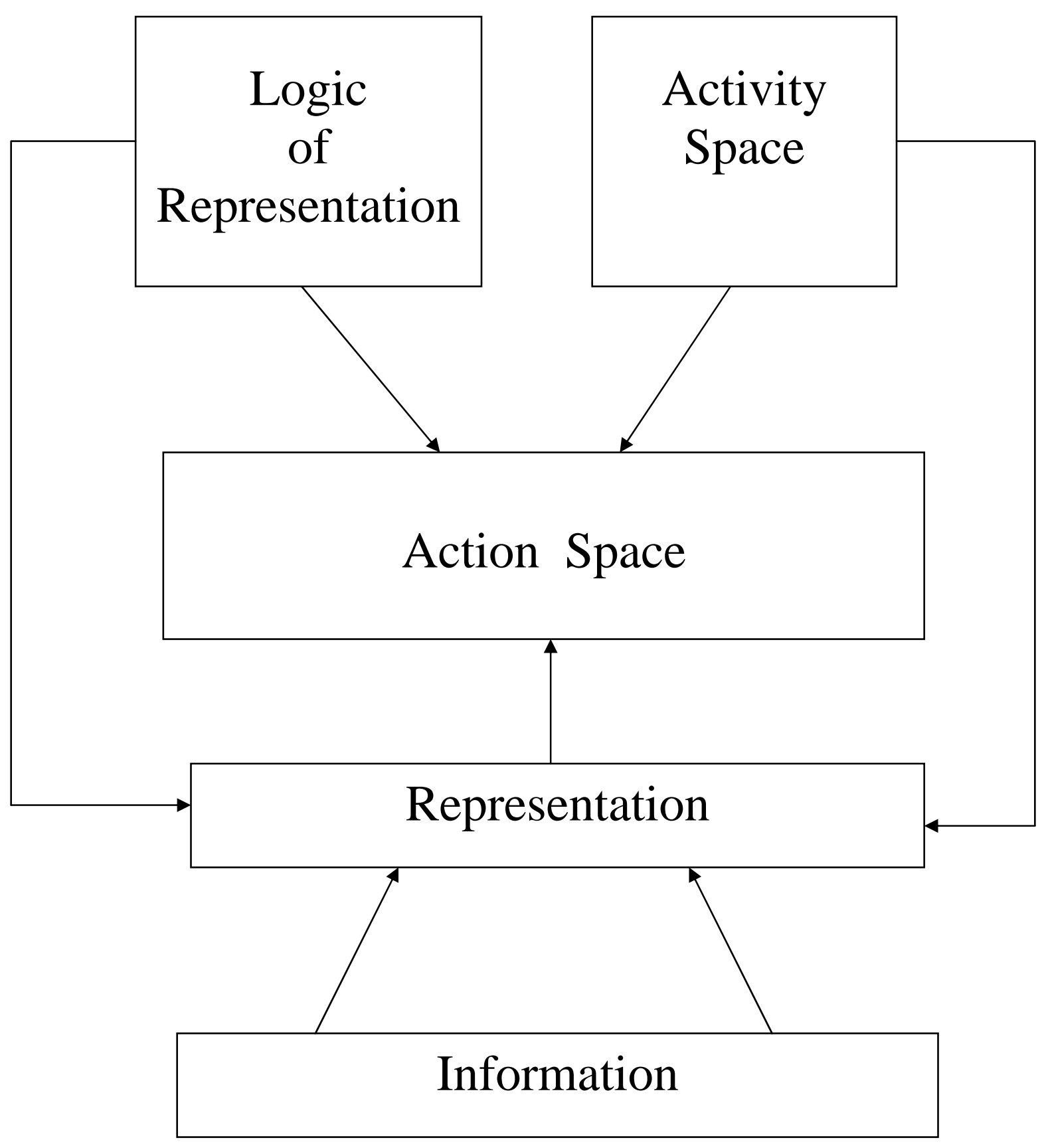


Figure 2. Parameters of Prototypical Actions Spaces

\begin{tabular}{|c|c|c|c|}
\hline Actions space & Operations/Legitimacy & $\begin{array}{l}\text { Market/Competitive } \\
\text { Advantage }\end{array}$ & $\begin{array}{l}\text { Enlightened } \\
\text { Management }\end{array}$ \\
\hline $\begin{array}{l}\text { Logic of } \\
\text { Representation } \\
\end{array}$ & Legitimacy & $\begin{array}{l}\text { Competitive } \\
\text { Advantage }\end{array}$ & $\begin{array}{l}\text { Enlightened } \\
\text { Management }\end{array}$ \\
\hline Objective & $\begin{array}{l}\text { Maintain license to } \\
\text { operate }\end{array}$ & $\begin{array}{l}\text { Maximized } \\
\text { shareholder economic } \\
\text { value }\end{array}$ & $\begin{array}{l}\text { Long term ecological } \\
\text { sustainability }\end{array}$ \\
\hline Decision Criteria & Input/output efficiency & Economic value & $\begin{array}{l}\text { Environmental impact } \\
\text { in light of long term } \\
\text { regenerative } \\
\text { capacities }\end{array}$ \\
\hline \multicolumn{4}{|l|}{$\begin{array}{l}\text { Environmental } \\
\text { Activity Space }\end{array}$} \\
\hline Time & Production cycle & Value chain cycle & Biogeneration cycle \\
\hline Space & Operations & Market & Ecosystem \\
\hline Inclusivity & Organization & Value chain partners & Relevant stakeholders \\
\hline $\begin{array}{l}\text { Environmental } \\
\text { orientation }\end{array}$ & Impediment & Means & End \\
\hline $\begin{array}{l}\text { Nature of long term } \\
\text { relationships }\end{array}$ & \begin{tabular}{|l}
$\begin{array}{l}\text { Self interested } \\
\text { efficiency }\end{array}$ \\
\end{tabular} & $\begin{array}{l}\text { Self interested } \\
\text { competition }\end{array}$ & Mutual cooperation \\
\hline
\end{tabular}


Figure 3. Framework for Environmentally Enlightened Accounting

\begin{tabular}{|c|c|c|}
\hline Operations/legitimacy & $\begin{array}{l}\text { Markets/competitive } \\
\text { advantage }\end{array}$ & $\begin{array}{l}\text { Stakeholder/enlightened } \\
\text { management }\end{array}$ \\
\hline $\begin{array}{l}\text { Volume of emissions and } \\
\text { effluents outputs, by unit } \\
\text { of production, point } \\
\text { source, and in aggregate. } \\
\text { Toxicity rating of } \\
\text { effluents and emissions. } \\
\text { - Amount of renewable } \\
\text { energy used for } \\
\text { production. } \\
\text { - Percentage of energy } \\
\text { usage from renewable } \\
\text { sources } \\
\text { Availability of renewable } \\
\text { energy. } \\
\text { Employee commuting and } \\
\text { business travel energy } \\
\text { usage and environmental } \\
\text { impact. } \\
\text { Incremental costs of } \\
\text { improving facility and } \\
\text { buildings energy } \\
\text { efficiency. } \\
\text { Incremental costs of } \\
\text { facility design and } \\
\text { construction using } \\
\text { renewable and/or recycled } \\
\text { materials. } \\
\text { Cost of environmental } \\
\text { management } \\
\text { administration }\end{array}$ & $\begin{array}{l}\text { - Cost of renewable energy } \\
\text { for product in-use. } \\
\text { Availability of renewable } \\
\text { energy for product in-use. } \\
\text { - Cost of renewable and/or } \\
\text { recyclable materials and } \\
\text { components for product. } \\
\text { - Availability of renewable } \\
\text { and/or recyclable } \\
\text { materials and components } \\
\text { for product. } \\
\text { - Amount of required } \\
\text { energy for life cycle of } \\
\text { products. } \\
\text { - Percentage of products } \\
\text { recyclable and/or } \\
\text { reusable. } \\
\text { Cost of take-back } \\
\text { systems. } \\
\text { Availability of take-back } \\
\text { systems }\end{array}$ & 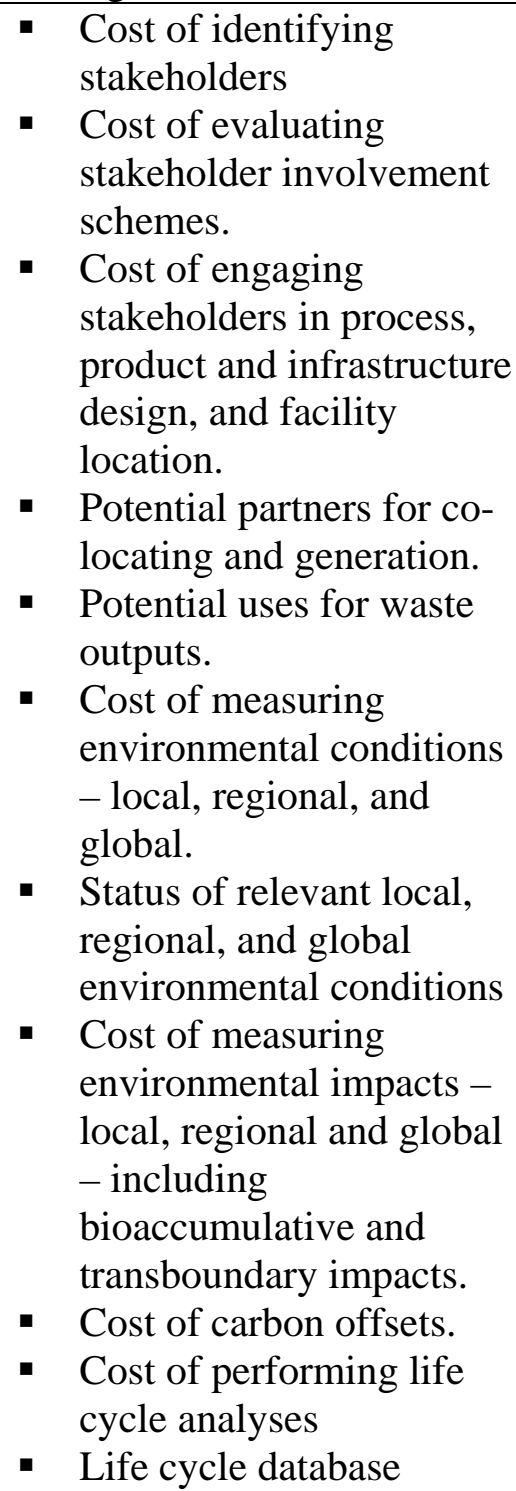 \\
\hline
\end{tabular}

